\title{
AVALIAÇÃO NACIONAL DA ALFABETIZAÇÃO: PRODUÇÃO E GERENCIAMENTO DO RISCO DO ANALFABETISMO INFANTIL
}

\author{
Renata Sperrhake \\ Samuel Edmundo Lopez Bello ${ }^{(*)}$
}

A Avaliação Nacional da Alfabetização integra as ações do Pacto Nacional pela Alfabetização na Idade Certa (PNAIC) e se configura como um dos seus eixos de atuação. É uma avaliação censitária que tem como público-alvo os alunos do $3^{\circ}$ ano do Ensino Fundamental das escolas urbanas e rurais das redes públicas de ensino que tenham mais de 10 alunos matriculados. Seu objetivo é aferir os níveis de alfabetização e letramento em Língua Portuguesa (leitura e escrita) e Matemática.

Do ponto de vista metodológico, buscando "inspiração em Foucault", este trabalho se propõe a interrogar o tempo presente a partir de alguns pressupostos da análise do discurso foucaultiana, quais sejam:

1) qualquer objeto discursivo tem uma história e faz parte do trabalho do pesquisador, que assume esse referencial, buscar e descrever a rede de relações que faz com que tal objeto ganhe visibilidade neste momento e não em outro; no caso desta pesquisa interessa discutir a visibilidade das práticas avaliativas em larga escala da alfabetização neste momento histórico;

2) O olhar direcionado ao material de pesquisa deve buscar pelas rupturas - as mudanças significativas que irrompem, deslocando significados, práticas, sujeitos - e, também, pelas permanências e pelas recorrências - aquilo que repetidamente é dito e aquilo que repetidamente "cala";

3) Uma atitude investigativa que procura tensionamentos, pontos de conflito.

Foi nesse sentido que se buscou olhar os documentos - portarias, notas explicativas, relatórios, etc. Nessa busca chegou-se à noção de risco do analfabetismo infantil. Neste texto, então, apresentamos as análises a respeito da quantificação, da produção e das estratégias de gerenciamento desse risco.

\footnotetext{
${ }^{(*)}$ Renata Sperrhake. Professora da Faculdade de Educação da Universidade Federal do Rio Grande do Sul (UFRGS) na Área de Formação Pedagógica e Linguagem. Pedagoga, mestre e doutora em Educação pelo PPGEDU/UFRGS.

Samuel Edmundo L. Bello. Licenciado em Matemática. Doutor em Educação Matemática pela Unicamp. Professor Associado IV da Faculdade de Educação e dos Programas de Pós Graduação em Educação (PPGEDU) e em Ensino de Ciências: Química da Vida e Saúde (PPGQVS/UFRGS). Coordenador do Grupo de Pesquisa CNPQ/ Praktiké.
} 


\section{ANALFALFABETISMO E ALFABETIZAÇÃO NO BRASIL: UM PROBLEMA QUE PERMANECE}

"Na história do Brasil, temos vivenciado a dura realidade de identificar que muitas crianças têm concluido sua escolarização sem estarem plenamente alfabetizadas" (Brasil, 2012, p. 5).

O debate acerca do analfabetismo no Brasil não é novo e percorre diversas áreas de estudo e pesquisa, desde a história da educação até perspectivas vinculadas ao ensino-aprendizagem e à formulação de políticas públicas. Ferraro (2009) refere-se à "tendência secular do analfabetismo" no Brasil, tendência essa produzida a partir dos dados numéricos do Censo e da Pesquisa Nacional por Amostra de Domicílios (PNAD).

A busca pela quantificação da população analfabeta vem ocorrendo desde o ano de 1872, no Brasil, com o primeiro recenseamento nacional. Conforme apontam Sperrhake e Traversini (2012) e Sperrhake (2013) há diferentes critérios utilizados para avaliar se uma pessoa, ou grupo, será considerada analfabeta ou alfabetizada: o critério usado para medir a alfabetização no Censo Demográfico apoia-se na resposta à pergunta "Sabe ler e escrever?” (autodeclaração). Há também a utilização do critério anos de estudo - utilizado apenas no questionário amostral do Censo; e, por fim, há as pesquisas que se utilizam de questionários e de provas ou testes para medir a alfabetização ou o alfabetismo, tais como Indicador Nacional de Alfabetismo Funcional (INAF) e o Programa Internacional de Avaliação de Estudantes (PISA). Temos, portanto, um movimento, já histórico, de busca por formas de quantificar tanto a população alfabetizada e analfabeta, quanto a própria alfabetização, mensurando o quanto as pessoas fazem uso do conhecimento linguístico em práticas sociais de leitura e escrita. Produzir dados sobre isso é apontado por Soares (2006, p.63) como uma necessidade "[...] tanto para evidenciar se os objetivos [de universalização da alfabetização] estão sendo alcançados como para estabelecer políticas ou controlar programas de alfabetização e letramento" (grifos nossos).

Em relação ao que significa ser alfabetizado nas quantificações do Censo - ter a capacidade de ler e escrever um bilhete simples - temos uma ampliação do que significa ser alfabetizado para o PNAIC, o qual considera a criança alfabetizada como um indivíduo que não

[...] domina apenas os rudimentos da leitura/escrita, ou seja, que é capaz de ler/escrever palavras. Espera-se, mesmo na mais tenra idade, que a pessoa alfabetizada seja capaz de ler e escrever em diferentes situações sociais, para que possa, então, inserir-se e participar ativamente de um mundo letrado, frente às demandas sociais e aos avanços da tecnologia, que exigem sujeitos cada vez mais proficientes nas práticas de linguagem diversas (BRASIL, 2012, p.26). 
A ampliação da abrangência do conceito de alfabetização se deve ao desenvolvimento do país em diversas esferas: social, econômica, cultural, política. Com isso, “[...] durante o século XX, ganham cada vez maior visibilidade as muitas e variadas demandas de leitura e de escrita nas práticas sociais e profissionais, gerando a necessidade de mais avançadas e diferenciadas habilidades de leitura e de escrita" (SOARES, 2016, p.26). Vemos, desse modo, que essa ampliação implica uma forte vinculação com os modos de agir do sujeito alfabetizado em práticas diversificadas envolvendo a leitura e a escrita, contribuindo para aquilo que poderíamos chamar de uma "formação cidadã". Nesse caso, finalizar o Ciclo de Alfabetização sem estar alfabetizado nesse sentido alargado - ou, então, como algumas pesquisas apontam ${ }^{1}$, finalizar o Ensino Fundamental sem essa aprendizagem, acarretaria um prejuízo ao indivíduo não apenas na sua trajetória escolar, mas também nas práticas da vida em sociedade. Não há apenas a ampliação do significado de um conceito, há a ampliação das possibilidades de ação de um tipo de sujeito - o sujeito alfabetizado - e, também, a ampliação da preocupação com a produção de sujeitos analfabetos, pois estes poderão não se inserir completamente na sociedade, tendo a sua atuação cidadã prejudicada. Desse modo,

A atenção voltada ao Ciclo de Alfabetização deve-se à concepção de que esse período é considerado necessário para que seja assegurado a cada criança o direito às aprendizagens básicas da apropriação da leitura e da escrita, e também à consolidação de saberes essenciais dessa apropriação, ao desenvolvimento das diversas expressões e ao aprendizado de outros saberes fundamentais das áreas e componentes curriculares obrigatórios (BRASIL, 2013a, p.5).

Na década de 1940, o analfabetismo para o país é apontado por Lourenço Filho como “[...] um fator de atraso nacional e, se não fosse combatido, temia-se que pudesse ameaçar os planos de progresso vislumbrados para o Brasil" (GIL, 2002, p.135). O que interessa destacar aqui é que a alfabetização, como aprendizagem da leitura e da escrita que capacitaria o sujeito a agir de uma maneira diferente na sociedade, se configura como um saber estratégico na constituição dos sujeitos contemporâneos, o que gera essa preocupação em torno do analfabetismo, do risco de sua produção, ou da manutenção de uma população analfabeta em pleno século XXI. Assim, a

[...] alfabetização assume foco central da escolarização, como recurso para o desenvolvimento da autonomia das pessoas para a busca de conhecimento mediado pela língua escrita. A alfabetização, enquanto base para a aquisição de outros conhecimentos escolares, concorre para a inserção das pessoas nos contextos letrados

\footnotetext{
${ }^{1}$ RIBEIRO; LIMA; BATISTA, 2015.
} 
da atualidade como elemento significativo para a formação da cidadania (BRASIL, 2015a, p.17).

De acordo com Hattge (2014, p.121), "No cenário mundial, cada vez mais, os países buscam melhores posições nos rankings educacionais. Organismos como a Unesco e o Banco Mundial entendem que o desempenho dos alunos na educação básica é um indicador importante do desenvolvimento das nações". A porta para uma melhoria no desempenho dos alunos nas avaliações da Educação Básica - nacionais e internacionais - seria a garantia de uma alfabetização - de qualidade.

A dimensão estratégica da alfabetização opera, também, em outro movimento: no investimento em capital humano, uma vez que "[...] as capacidades pessoais e subjetivas dos cidadãos têm sido incorporadas aos objetivos e aspirações dos poderes públicos” (ROSE, 1998, p.31). Podemos considerar, junto com Foucault (2008), que a teoria do capital humano transpõe para o âmbito da economia aspectos da vida que antes não o pertenciam. Assim, a alfabetização configura-se como um saber estratégico também para o desenvolvimento do "capital humano", pois ela seria uma habilidade ou capacidade por meio da qual o indivíduo poderia, além de ter sucesso na sua escolarização, o que elevaria os índices educacionais nacionais e internacionais, se tornar um sujeito com mais possibilidades de atuação como cidadão autônomo e mais produtivo para o país. Nesse sentido, "a subjetividade faz parte dos cálculos das forças políticas” (ROSE, 1998, p.31), o que leva a um controle e regulação da "[...] conduta dos cidadãos através de uma ação sobre suas capacidades e propensões mentais" (ROSE, 1998, p.31). No caso aqui analisado, leva a um controle e regulação das capacidades leitoras e escritoras dos indivíduos.

Não alcançar a alfabetização das crianças seria, pela argumentação aqui apresentada, no mínimo, problemático. Vemos, então, a divulgação de dados referentes ao ano de 2011 apontando que "[...] 56,1\% dos estudantes haviam aprendido aquilo que era esperado em leitura; 53,3\% em escrita; 42,8\% em matemática" (TODOS PELA EDUCAÇÃO, 2011, p.76). As estatísticas produzidas sobre a alfabetização das crianças visibilizam um problema e dão a ele uma magnitude que, sem a objetivação em dados numéricos, talvez não pudesse ser percebida da maneira desejada.

A operação de transformação da expectativa "qualitativa" da alfabetização para o âmbito do quantitativo permite criar um quadro de preocupação e incerteza - com o ensino, com os professores, com a aprendizagem das crianças, com suas condições de vida, entre outros. Cria-se $o$ risco da produção do analfabetismo infantil. Segundo Bello e Sperrhake (2016, p.419), risco é “um problema para o qual se deve ter uma atitude". Os autores argumentam que "[...] há uma concepção 
de risco associado à ideia de regressão social que conduz a prestar uma atenção especial ao cotidiano" (BELLO; SPERRHAKE, 2016, p.419). É nesse sentido que se enquadra o risco do analfabetismo infantil, risco este criado em uma articulação entre discurso pedagógico, discurso político e discurso técnico-científico. Este último envolvendo saberes estatísticos e processos classificatórios, capazes de objetivar e dar a conhecer uma situação como problema.

A estatística pode ser entendida como um meio, composto por saberes e por procedimentos técnicos específicos que é utilizada por governos das diferentes esferas públicas, para situar comunidades com altos índices de analfabetismo, por exemplo, como sendo de risco social. Analisar como se conduz a conduta desse conjunto de indivíduos para sair dessa condição de analfabetismo é tomar a prática da gestão do risco como uma forma de governar que necessita do saber estatístico para tomar decisões (TRAVERSINI; BELLO, 2009, p.143).

Como base para a tomada de decisões, as estatísticas produzem “[...] um diagnóstico de alfabetização e letramento em Língua Portuguesa e alfabetização em Matemática, ao final do Ciclo de Alfabetização [...]” (BRASIL, 2013a, p.5). Esse diagnóstico se configura como um dos objetivos da ANA, especialmente da sua primeira edição em 2013, que deveria “[...] servir como "linha de base" para a implementação das políticas previstas no Pacto, auxiliando na orientação permanente da formação de professores alfabetizadores" (BRASIL, 2013a, p.14).

A partir desse diagnóstico, uma das maneiras para reverter a situação arriscada do analfabetismo da população infantil é a criação de políticas públicas destinadas a isso, pois “os números definem trajetórias para sinalizar progressos ou identificar locais potenciais de intervenção por meio de políticas de estado" (POPKEWITZ; LINBDLAD, 2001, p.115). Essa é uma maneira mais evidente, que funciona do macro ao micro. Afora essa estratégia mais explícita e mais ampla, há outras mais sutis, que convocam os sujeitos a se aliarem ao objetivo de alfabetizar as crianças e a combater o risco do analfabetismo infantil. Essas estratégias serão apresentadas nas próximas seções.

\section{PRIMEIRA ESTRATÉGIA: VISIBILIDADE E VIGILÂNCIA DO RISCO}

A primeira dessas estratégias é justamente a exposição dos dados estatísticos, produzidos a partir dos testes de desempenho das práticas avaliativas em larga escala, pela mídia. Essa estratégia de visibilização do risco e do problema do analfabetismo infantil irá colocar em funcionamento um conjunto de dizibilidades, tornando-o existente, pois 
“[...] quando alguém, um locutor de rádio ou de televisão, lhe anuncia alguma coisa, o senhor acredita ou não acredita, mas isso se põe a funcionar na cabeça de milhares de pessoas como verdade, unicamente porque foi pronunciado daquela maneira, naquele tom, por aquela pessoa, naquela hora" (FOUCAULT, 2015, p.228).

Nesse sentido apontado por Foucault, não importa se o percentual representa ou não efetivamente a quantidade de crianças sem a aprendizagem considerada adequada; não importa se o dado numérico é ou não "verdadeiro". O que interessa é o efeito de verdade produzido, o que interessa é a sua existência no seu funcionamento como verdade, uma vez que convoca e mobiliza os indivíduos a pensarem a respeito da alfabetização de crianças e, mais do que isso, coloca o problema em discurso, e em discurso numérico; insere-o na pauta. Castro (2015, p.132) aponta que os resultados das avaliações, divulgados de forma "ampla e transparente" têm apresentado impactos na opinião pública e nas escolas, onde “[...] professores, alunos e dirigentes já se preocupam em discutir os indicadores de sua escola ou município" (2015, p.132).

Nessa linha, o Observatório do $\mathrm{PNE}^{2}$ apresenta os dados obtidos na ANA e a meta estabelecida pelo Plano Nacional de Educação, fazendo funcionar uma estratégia de monitoramento e vigilância.

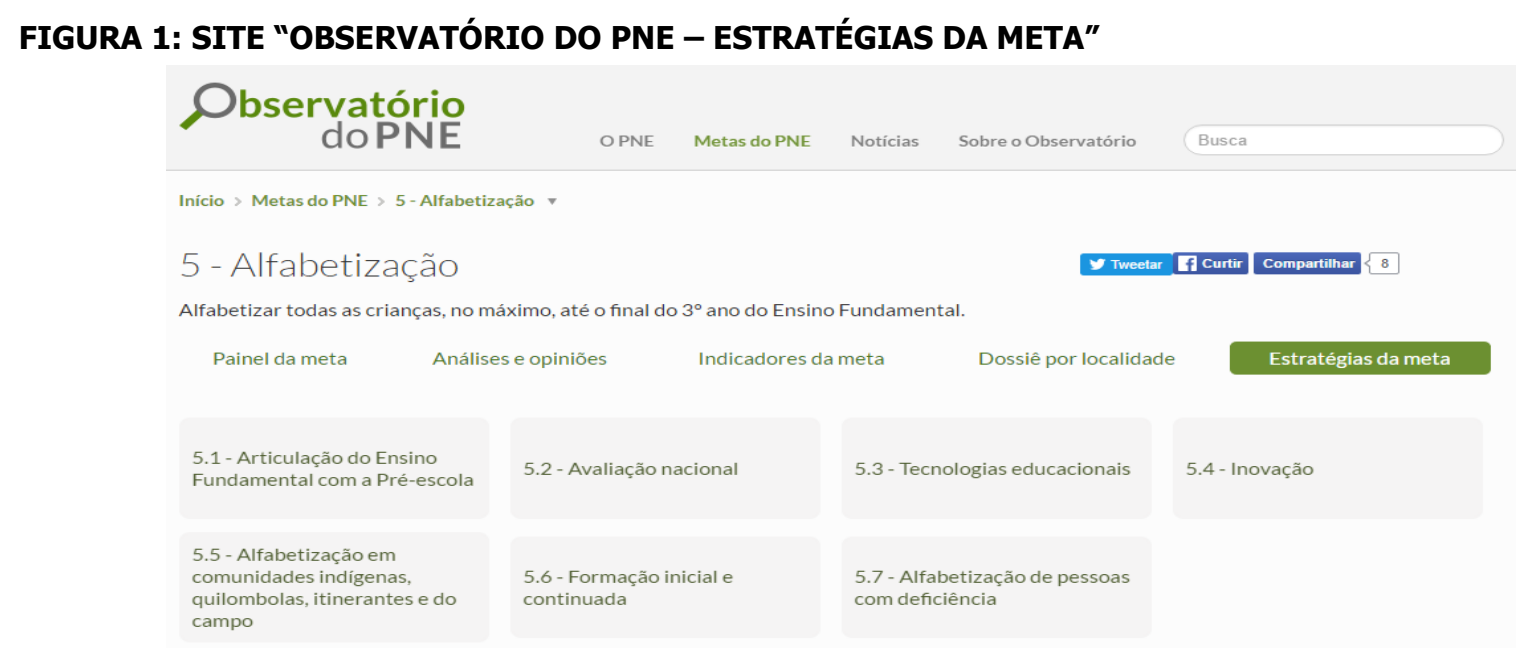

Fonte: http://www.observatoriodopne.org.br/metas-pne/5-alfabetizacao/estrategias

Foucault (2009) argumenta que na prática de ensino existe uma relação de fiscalização que lhe é inerente. Apesar de o autor estar tratando, neste momento de sua obra, das práticas disciplinares operadas no interior de instituições, podemos considerar que há a invenção constante de novas maneiras de exercer um mecanismo de vigilância. No caso aqui apresentado, amplia-se o papel de vigia para toda a sociedade, desinstitucionalizando o mecanismo de vigilância

\footnotetext{
${ }^{2}$ Disponível em: 〈http://www.observatoriodopne.org.br >
} 
(FOUCAULT, 2009): todos são responsáveis por acompanhar a meta da alfabetização. Ao utilizar gráficos e informações estatísticas, o "Observatório do PNE” convoca a sociedade a conhecer a situação educacional do país, expõem os problemas e, mais do que isso, estabelece metas. Indica onde os índices devem chegar.

\section{FIGURA 2: SITE "OBSERVATÓRIO DO PNE - PAINEL DA META"}

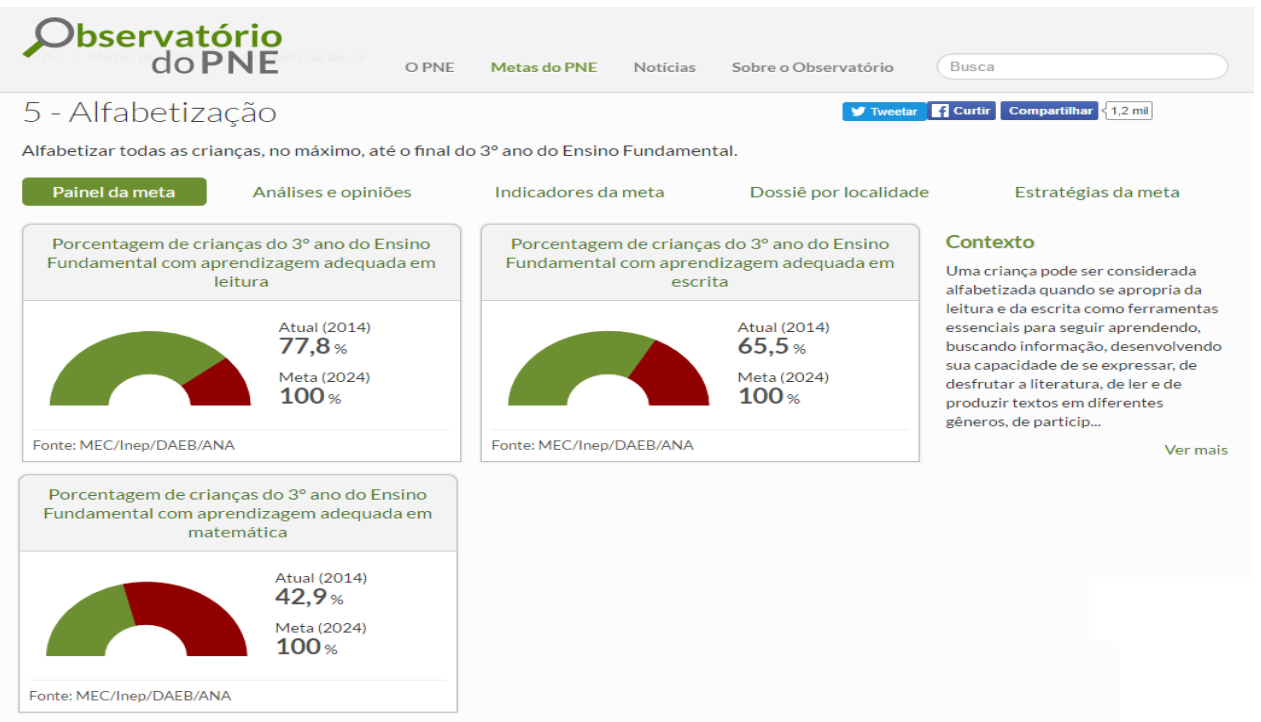

Fonte: http://www.observatoriodopne.org.br/metas-pne/5-alfabetizacao

Há uma convocação do indivíduo para que este supervisione a meta de alfabetização, saiba quais são as estratégias traçadas para alcançá-la, conheça os dados da sua região, acesse a "opinião dos especialistas" a respeito do tema. Há a construção de uma trama discursiva para combater o risco do analfabetismo infantil que não fica restrita aos administrados, aos propositores de políticas públicas, aos gestores educacionais. Todos e cada um podem, e devem, monitorar os dados sobre a alfabetização das crianças.

\section{SEGUNDA ESTRATÉGIA: A APRENDIZAGEM COMO DIREITO}

Se até mais da metade do século XX o problema do analfabetismo tinha como algumas de suas causas a falta de acesso à escolarização, a repetência e a evasão, no início do século XXI esse problema se desloca para as questões da aprendizagem e do ensino, visto que o acesso à escolarização básica se torna universal e o problema da permanência se retrai. Desse modo, as formas de intervenção das políticas públicas passam a ter como alvo não mais (apenas) o ingresso e a manutenção das crianças na escola, mas a garantia de que as aprendizagens ocorram, e no tempo previsto para isso. Para ambos os problemas, as estatísticas tiveram a sua importância. 
Até os anos 1980, o fracasso na alfabetização de crianças era "revelado" pelas avaliações produzidas no interior da instituição escolar, era focalizado na série ou ano inicial da escolarização fundamental - geralmente chamada de classe de alfabetização (SOARES, 2016). Gil (2007, p. 176) aponta que, por volta de 1940, “[...] assumia-se a alfabetização escolar como correspondente ao total de alunos frequentando a segunda série ao final do ano letivo (matrícula efetiva)". Havia, porém, uma limitação ao se considerar a aprovação ou a matrícula na $1^{\mathrm{a}}$ ou na $2^{\mathrm{a}}$ série como critério para inferir a alfabetização das crianças: essas informações não "garantiam" se havia ocorrido aprendizagem da leitura e da escrita. Já no início do século XXI, o fracasso na alfabetização vem sendo apresentado através de práticas avaliativas externas de larga escala

[...] e já não se concentra mais na série inicial da escolarização, mas espraia-se ao longo de todo o ensino fundamental, chegando mesmo ao ensino médio, traduzido em altos índices de precário ou nulo domínio da língua escrita, evidenciando grandes contingentes de alunos não alfabetizados ou semialfabetizados depois de quatro, seis, oito anos de escolarização (SOARES, 2016, p. 23-24).

A produção dos números a partir dessa prática avaliativa evidenciaria a existência de um risco, estatisticamente comprovado, demandando que haja uma ação a respeito desse risco, e a garantia de que esse risco será combatido se faz pela via do direito das crianças à aprendizagem: “Todas essas ações dirigem-se a um propósito: 'garantir que todos os estudantes dos sistemas públicos de ensino estejam alfabetizados, em Língua Portuguesa e em Matemática, até o final do $3^{\circ}$ ano do ensino fundamental' (art. 5', inciso I)" (BRASIL, 2013a, p.5).

Castro argumenta que "A experiência internacional, assim como a brasileira, mostra que as ações mais eficazes para a melhoria da qualidade do ensino são as focadas na aprendizagem e na escola" (CASTRO, 2015, p.132). É desse modo que se justifica o "[...] contexto de atenção voltada à alfabetização prevista no Pacto Nacional pela Alfabetização na Idade Certa (PNAIC)" (BRASIL, 2013a, p.5). Ao tomar a alfabetização como um saber estratégico para a produção de capital humano e para aumento das forças do Estado, esse direito à aprendizagem "[....] não é uma benesse oferecida pelo Estado; ele só é legitimado quando vai ao encontro de conter situações individuais que possam gerar um risco coletivo" (CAMINI, 2015, p.137).

Ao analisar o deslocamento sofrido no sentido da aprendizagem, nas políticas públicas e no Movimento Todos Pela Educação, passando a ser compreendida como um direito, Hattge (2014) argumenta que

No momento em que o aprendizado se torna um direito, a única forma encontrada pelo Movimento [Todos Pela Educação] para "garantir" esse direito é o monitoramento 
constante desse aprendizado através de sistemas de avaliação em larga escala que permitem a análise dos níveis de desempenho de todos e de cada um (HATTGE, 2014, p.131).

Cabe ressaltar que o Pacto Nacional Pela Alfabetização na Idade Certa, nos materiais destinados à formação de professores, elenca diversas listas de "direitos de aprendizagem" a serem garantidos pelas escolas aos alunos alfabetizandos. Garantir a aprendizagem como um direito do aluno, devendo, portanto, ser oferecido pelo professor, pela escola, pela rede e sistema de ensino, configura-se como uma estratégia para administrar o risco do analfabetismo infantil, uma vez que a aprendizagem, de certa forma, seria uma garantia de bons resultados nas avaliações que medem essa alfabetização/analfabetismo, ainda que não haja uma certeza dos resultados. Para maximizar os efeitos positivos e promover a contenção do risco, quanto mais informação se dispuser - e quanto mais detalhadas elas forem -, mais eficazes serão as ações. E é nesse sentido que atua a terceira estratégia, detalhada a seguir.

\section{TERCEIRA ESTRATÉGIA: A COMPARAÇÃO}

O risco do analfabetismo infantil, contudo, não se distribui de maneira equitativa no território nacional. Poderia se pensar que as escolas com maior dificuldade em promover as aprendizagens concernentes ao Ciclo de Alfabetização seriam aquelas que atendem ao público também considerado como de risco social, em relação à pobreza, por exemplo. Desse modo, o que fazer para minimizar o risco do analfabetismo infantil nesses locais? Primeiramente, localizá-los.

FIGURA 3. DISTRIBUIÇÃO PERCENTUAL DOS ESTUDANTES NOS NÍVEIS DE PROFICIÊNCIA EM LEITURA NA EDIÇÃO DE 2014 DA ANA, POR REGIÃO GEOGRÁFICA E UF 


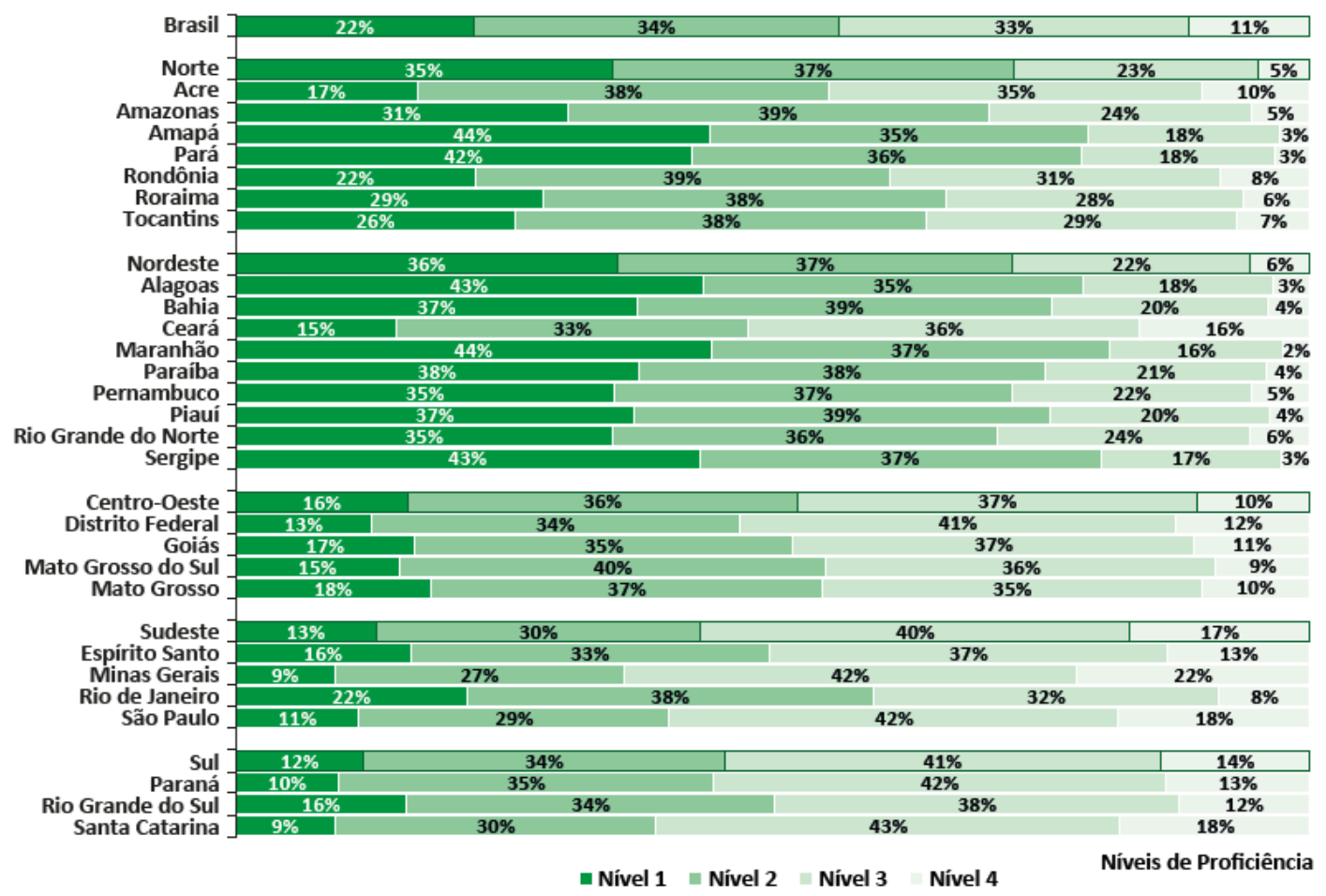

Fonte: INEP (BRASIL, 2015b, p.41).

\section{FIGURA 4. NÍVEL DE PROFICIÊNCIA PREDOMINANTE DOS ESTUDANTES EM LEITURA NA EDIÇÃO DE 2014 DA ANA, POR MUNICÍPIO}

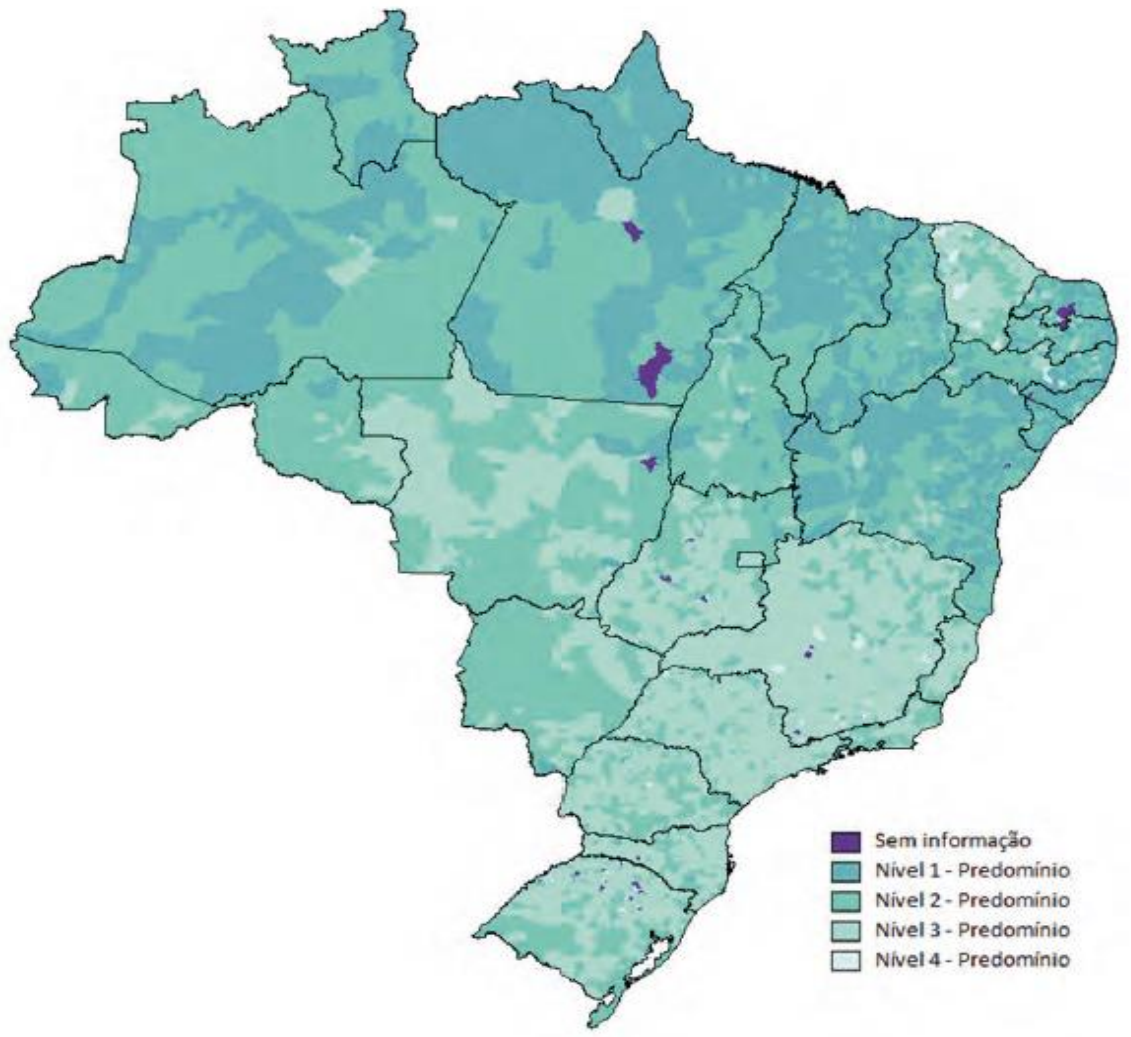

Fonte: INEP (BRASIL, 2015b, p.50). 
Os resultados da ANA são apresentados mostrando a distribuição dos percentuais de estudantes em cada nível das escalas de proficiência de acordo com vários critérios: por estado, por UF, por categoria administrativa (municipal, estadual ou federal), por área (urbana ou rural), por localização (capital ou interior), por município. Porém, essa não é a única forma de localizar o risco do analfabetismo infantil.

As práticas avaliativas em larga escala buscam integrar os resultados de testes de desempenho às condições escolares e às condições socioculturais e socioeconômicas dos alunos com o objetivo de ampliar o espectro de monitoramento da qualidade da educação básica, marcando, desse modo, os locais nos quais o risco do analfabetismo se mostra mais evidente. As práticas de medição e os processos de classificação mobilizados pelo arsenal estatístico utilizado pelas avalições em larga escala, ampliam a possibilidade de realizar comparações dos mais diversos tipos, tais como entre escolas com nível socioeconômico próximo, ou que estejam na mesma região geográfica ou que possuam matrículas em quantidades semelhantes. À vista disso, "[...] não se trata apenas de produzir e divulgar dados estatísticos sobre o resultado do desempenho de alunos e escolas, comparando-os indiscriminadamente" (LOCKMANN, 2017), a finalidade das práticas avaliativas em larga escala é produzir informações que sejam comparáveis no tempo, entre regiões, entre países, entre estados, entre "escolas similares”, e não considerando apenas os resultados dos testes de desempenho, mas aliando esses dados a outros. Dessa forma, foge-se da crítica muitas vezes direcionada às práticas avaliativas em larga escala, de que não se poderiam comparar resultados de escolas, cidades ou estados com realidades distintas, produzindo-se estatísticas que visam estabelecer a contextualização dos resultados obtidos nos testes, movimento este que Lockmann (2013) nomeou de "semelhança imaginada". A autora argumenta que a estatística produz grupos através de uma “[...] semelhança imaginada, a qual destaca traços, perfis e características que são relacionadas a grupos específicos com o intuito de encontrar similitudes e poder agrupá-los em conjunto. Agrupando-os torna-se mais fácil agir sobre eles para controlar e governar" (LOCKMANN, 2013, p.99).

O movimento de aliar os resultados dos desempenhos dos alunos com dados contextuais não é exclusividade da ANA, tampouco é algo que aparece apenas nesses últimos anos. Desde as primeiras iniciativas de produção de práticas avaliativas em larga escala no Brasil há a preocupação com a produção de estatísticas que medissem as condições de oferta do ensino e as condições de vida dos estudantes. 
Há um esforço de produção de informações numéricas além das provenientes dos testes de desempenho realizados pelos estudantes. A justificativa para a necessidade desses indicadores, segundo o INEP, está embasada em estudos que estabelecem correlações positivas entre o “[...] nível socioeconômico dos estudantes, ao lado de outros fatores, tais como atraso escolar e cor/etnia" (BRASIL, 2014, p.3) com o desempenho em testes cognitivos. O estudo de Soares e Alves (2013), com dados da Prova Brasil de 2005 a 2011, mostrou que o nível socioeconômico da escola é importante no desempenho dos alunos nos testes, e não apenas o nível socioeconômico do aluno e sua família. Os autores concluem afirmando que “[...] não se pode analisar qualidade em educação sem considerar as características dos alunos e o contexto das escolas" (SOARES; ALVES, 2013, p.513), e que a melhora na qualidade da educação está mais vinculada à eficácia do uso dos recursos do que a sua quantidade. Nesse sentido, “[...] os números fornecem uma maneira de raciocinar a respeito da relação entre fenômenos sociais e educacionais" (POPKEWITZ; LINDBLAD, 2001, p. 115), produzindo correlações que são vistas como confiáveis, pois são fruto da racionalidade científica da estatística.

A partir dessa concepção ampliada de avaliação, denotando que o conjunto de determinantes da aprendizagem supera a dimensão cognitiva e se vincula ao contexto no qual a criança se insere, pretende-se delinear a proposta de avaliação no âmbito do Pacto Nacional pela Alfabetização na Idade Certa (PNAIC) [...] (BRASIL, 2013a, p. 14).

Para tanto a ANA se vale de dois questionários, um para os gestores da escola e outro para os professores alfabetizadores, que visa à produção de informações sobre as condições de oferta do Ciclo de Alfabetização. Além desses, a ANA também utiliza os questionários da Prova Brasil/ANRESC, do ENEM e os dados do Censo Escolar para produzir o Indicador Socioeconômico - INSE ${ }^{3}$. Tal indicador já tem sido divulgado junto com os dados da Prova Brasil, do ENEM e do IDEB, desde 2014. Além do INSE, a ANA traça o "perfil das escolas similares” e produz o "indicador de esforço docente", o "indicador de complexidade de gestão", o "indicador de formação docente" e o "indicador de regularidade docente"

Convém aqui destacar o perfil de "escolas similares" que "[...] sintetiza os resultados de um grupo de escolas com características semelhantes” (BRASIL, 2013b, p.1). Essa semelhança é

\footnotetext{
3 “O indicador de Nível Socioeconômico possibilita, de modo geral, situar o público atendido pela escola em um estrato ou nível social, apontando o padrão de vida referente a cada um de seus estratos. Esse indicador é calculado a partir da escolaridade dos pais e da posse de bens e contratação de serviços pela família dos estudantes. Para melhor caracterizar as escolas foram criados sete grupos, que engloba desde as escolas que possuem nível socioeconômico Muito Baixo até as que possuem nível Muito Alto" (INEP). Disponível em: <http://ana.inep.gov.br/ANA/

${ }^{4}$ Para uma caraterização desses indicadores ver http://ana.inep.gov.br/ANA/>
} 
baseada na localização geográfica (microrregião segundo o IBGE e se urbana ou rural) e no valor absoluto do INSE. A análise produzida pelo INEP situa uma escola qualquer em relação às oito escolas com INSE absoluto imediatamente inferior e às oito escolas com INSE absoluto imediatamente superior, compondo, dessa forma, um subgrupo a partir do qual o Perfil de "Escolas Similares" será calculado considerando a quantidade de alunos em cada nível e a média ponderada das proficiências médias, pela quantidade de alunos.

FIGURA 5. EXEMPLO DE PERFIL DE ESCOLAS SIMILARES POR NÍVEL DE PROFICIÊNCIA

\begin{tabular}{|c|c|c|c|c|c|c|c|c|c|}
\hline $\begin{array}{l}\text { Subgrupo das } \\
\text { "Escolas Similares" } \\
\text { referentes à } \\
\text { Escola } 38 \\
\end{array}$ & $\begin{array}{c}\% \text { de } \\
\text { Alunos } \\
\text { no } \\
\text { Nivel } 1 \\
\end{array}$ & $\begin{array}{l}\text { Quantidade } \\
\text { de Alunos }\end{array}$ & $\begin{array}{c}\% \text { de } \\
\text { Alunos } \\
\text { no } \\
\text { Nivel } 2 \\
\end{array}$ & $\begin{array}{l}\text { Quantidade } \\
\text { de Alunos }\end{array}$ & $\begin{array}{c}\% \text { de } \\
\text { Alunos } \\
\text { no } \\
\text { Nivel } 3 \\
\end{array}$ & $\begin{array}{l}\text { Quantidade } \\
\text { de Alunos }\end{array}$ & $\begin{array}{c}\% \text { de } \\
\text { Alunos } \\
\text { no } \\
\text { Nivel } 4 \\
\end{array}$ & $\begin{array}{l}\text { Quantidade } \\
\text { de Alunos }\end{array}$ & $\begin{array}{l}\text { Total } \\
\text { de } \\
\text { Alunos }\end{array}$ \\
\hline Escola 30 & $75,0 \%$ & 22 & $25,0 \%$ & 7 & $0,0 \%$ & 0 & $0,0 \%$ & 0 & 29 \\
\hline Escola 31 & $100,0 \%$ & 48 & $0,0 \%$ & 0 & $0,0 \%$ & 0 & $0,0 \%$ & 0 & 48 \\
\hline Escola 32 & $38,5 \%$ & 22 & $38,5 \%$ & 22 & $23,1 \%$ & 13 & $0,0 \%$ & 0 & 58 \\
\hline Escola 33 & $80,0 \%$ & 22 & $20,0 \%$ & 6 & $0,0 \%$ & 0 & $0,0 \%$ & 0 & 28 \\
\hline Escola 34 & $50,0 \%$ & 23 & $37,5 \%$ & 17 & $12,5 \%$ & 6 & $0,0 \%$ & 0 & 46 \\
\hline Escola 35 & $71,4 \%$ & 59 & $28,6 \%$ & 24 & $0,0 \%$ & 0 & $0,0 \%$ & 0 & 83 \\
\hline Escola 36 & $100,0 \%$ & 56 & $0,0 \%$ & 0 & $0,0 \%$ & 0 & $0,0 \%$ & 0 & 56 \\
\hline Escola 37 & $27,3 \%$ & 11 & $45,5 \%$ & 18 & $27,3 \%$ & 11 & $0,0 \%$ & 0 & 39 \\
\hline \multicolumn{10}{|l|}{ Escola 38} \\
\hline Escola 39 & $72,7 \%$ & 24 & $27,3 \%$ & 9 & $0,0 \%$ & 0 & $0,0 \%$ & 0 & 33 \\
\hline Escola 40 & $44,4 \%$ & 28 & $55,6 \%$ & 34 & $0,0 \%$ & 0 & $0,0 \%$ & 0 & 62 \\
\hline Escola 41 & $50,0 \%$ & 23 & $50,0 \%$ & 23 & $0,0 \%$ & 0 & $0,0 \%$ & 0 & 46 \\
\hline Escola 42 & $54,8 \%$ & 53 & $19,1 \%$ & 19 & $26,1 \%$ & 25 & $0,0 \%$ & 0 & 97 \\
\hline Escola 43 & $44,4 \%$ & 24 & $55,6 \%$ & 31 & $0,0 \%$ & 0 & $0,0 \%$ & 0 & 55 \\
\hline Escola 44 & $33,3 \%$ & 10 & $33,3 \%$ & 10 & $33,3 \%$ & 10 & $0,0 \%$ & 0 & 29 \\
\hline Escola 45 & $85,7 \%$ & 39 & $14,3 \%$ & 7 & $0,0 \%$ & 0 & $0,0 \%$ & 0 & 46 \\
\hline Escola 46 & $71,4 \%$ & 62 & $14,3 \%$ & 12 & $14,3 \%$ & 12 & $0,0 \%$ & 0 & 87 \\
\hline $\begin{array}{l}\text { "Sua Escola" } \\
\text { (Escola 38) }\end{array}$ & $50 \%$ & 25 & $50 \%$ & 25 & $0 \%$ & 0 & $0,0 \%$ & 0 & 50 \\
\hline $\begin{array}{l}\text { Perfil de } \\
\text { "Escolas Similares" }\end{array}$ & $62,5 \%$ & 526 & $28,4 \%$ & 239 & $9,1 \%$ & 77 & $0,0 \%$ & 0 & 842 \\
\hline
\end{tabular}

Fonte: INEP (BRASIL, 2013b, p.5).

FIGURA 6 - EXEMPLO DE PERFIL DE ESCOLAS

SIMILARES POR PROFICIÊNCIA MÉDIA DA

ESCOLA 


\begin{tabular}{|c|c|c|}
\hline $\begin{array}{c}\text { Subgrupo das } \\
\text { "Escolas Similares" } \\
\text { referentes à } \\
\text { Escola 38 }\end{array}$ & $\begin{array}{c}\text { Quantidade } \\
\text { de Alunos }\end{array}$ & $\begin{array}{c}\text { Proficiência } \\
\text { Média da } \\
\text { Escola }\end{array}$ \\
\hline
\end{tabular}

\begin{tabular}{|l|l|l|}
\hline Escola 30 & 29 & 286,0 \\
Escola 31 & 48 & 270,0 \\
Escola 32 & 58 & 191,0 \\
Escola 33 & 28 & 298,0 \\
Escola 34 & 46 & 175,0 \\
Escola 35 & 83 & 209,0 \\
Escola 36 & 56 & 181,0 \\
Escola 37 & 39 & 221,0 \\
\hline Escola 38 & 33 & \\
\hline Escola 39 & 62 & 181,0 \\
Escola 40 & 46 & 245,0 \\
Escola 41 & 97 & 287,0 \\
Escola 42 & 55 & 205,0 \\
Escola 43 & 29 & 261,0 \\
Escola 44 & 46 & 258,0 \\
Escola 45 & 87 & 244,0 \\
\hline Escola 46 & & \\
\hline
\end{tabular}

\begin{tabular}{|c|c|c|}
\hline $\begin{array}{l}\text { "Sua Escola" } \\
\text { (Escola 38) }\end{array}$ & 50 & 225,0 \\
\hline $\begin{array}{l}\text { Perfil de } \\
\text { "Escolas Similares" }\end{array}$ & 842 & 228,1 \\
\hline
\end{tabular}

Fonte: INEP (BRASIL, 2013b, p. 6).

Para governar de maneira mais eficiente o Estado precisa produzir informações que forneçam a ele as áreas onde investir, as regiões problemáticas, as populações em risco, pois “os números governam [...] não como 'puros' números, mas por meio do entrecruzamento dos discursos paralelos que circulam pelos relatórios para traçar o perfil e inventariar pessoas" (POPKEWITZ; LINDBLAD, 2001, p. 126). Apenas os resultados dos testes de desempenho, de cada escola, não favoreceriam ações pontuais. A produção de mais informações estatísticas e a correlação entre essas informações permite uma "economia de governo", ou seja, através do mapeamento de áreas de ação, do estabelecimento de perfis e identificação daqueles nos quais se precisa investir, permite-se que se governe com ações mais precisas e direcionadas.

A construção de distinções mais sutis fornece maneiras mais específicas e detalhadas de ordenar a individualidade [...] As distinções mais sutis dos agrupamentos internos na escolaridade permitem calcular melhor a população sobre a qual trabalhar e permitem, assim, aumentar as possibilidades de governança de inclusão e exclusão (POPKEWITZ; LINDBLAD, 2001, p. 124).

O INSE e o Perfil de Escolas Similares agregam conhecimentos produzidos estatisticamente aos resultados dos testes das práticas avaliativas em larga escala, ao buscar contextualizá-las. Para que o Estado aumente as suas forças a partir da melhoria da educação da população, tornando-a alfabetizada, "um tal conhecimento era [é] indispensável ao bom governo" 
(FOUCAULT, 2015, p.369) [grifo meu], pois “O monitoramento da qualidade da educação básica, por meio de indicadores, é uma atividade essencial para a orientação e a avaliação das políticas públicas educacionais e das formas de gestão dos sistemas de ensino do país” (BRASIL, 2014, p.1). Assim,

Os dados permitem que as escolas se comparem não só com as escolas do mesmo município ou estado - como hoje é possível por meio dos dados divulgados - mas também a partir de características semelhantes: localização, dependência administrativa ou indicadores de complexidade de gestão e nível socioeconômico INEP, 2015) ${ }^{5}$.

Todos esses índices convidam à comparação, pois “[...] o conceito de comparação é constituinte do índice como produto estatístico, as próprias medidas obtidas a partir dos dados estatísticos são resultados de comparação com unidades ou sistema-padrão consideradas desejáveis" (BELLO, 2012, p.23). A maneira de agir sobre as práticas é convocando os indivíduos a compararem os desempenhos de seus alunos e de suas escolas com outras com as mesmas características, a partir desses "dados" contextualizados produzidos pelo INEP. A forma de provocar as condutas desejadas não se faz incidindo o governo diretamente sobre os indivíduos, mas modificando as práticas, neste caso, as práticas de avaliação - de medida e de classificação que, por sua vez, conduzem os indivíduos a agirem de formas diferentes. Ao se propor comparar escolas com perfis similares, a busca pelas razões das diferenças de desempenho, cada vez mais, passa a estar circunscrita ao âmbito da própria escola e das práticas pedagógicas e de gestão lá desenvolvidas. Se a garantia da aprendizagem pelas crianças é uma estratégia de prevenção e de combate ao risco do analfabetismo infantil, as comparações, assim propostas, colocam o foco nas práticas desenvolvidas nas escolas com índices mais favoráveis. Duas estratégias complementares que indicam, apesar de todos os fatores que podem estar correlacionados à qualidade da educação, que o foco não deixa de estar no ensino e na aprendizagem. Em outras palavras, ao convidar à comparação em meio a essa "semelhança imaginada" (LOCKMANN, 2013), o que é posto em cheque, o que se torna alvo de atenção, são as práticas (docentes, administrativas, gestoras, pedagógicas, avaliativas, etc.) exercidas nesses contextos.

Popkewitz e Lindblad (2001, p. 120) alertam que "Por meio de comparações educacionais numéricas constroem-se também ideais e fracassos educacionais" e, com todos esses indicadores associados aos resultados dos testes de desempenho, estabelecem-se classificações mais sutis a

\footnotetext{
${ }^{5}$ Disponível em: <http://portal.inep.gov.br/visualizar/-/asset_publisher/6AhJ/content/novo-portal-mostra-desempenhode-escolas-em-seu-contexto-social $>$.
} 
partir de distinções mais precisas e pontuais, que, por sua vez, formam um quadro de inteligibilidade do problema do analfabetismo infantil. A partir deste quadro, bem delimitado pelos indicadores estatísticos, o processo de governamento pode se exercer cada vez mais no detalhe.

FIGURA 7. COMPARAÇõES A PARTIR DAS MÉDIAS DAS ESCOLAS EM RELAÇÃo AO INSE

BRASIL Média por escola na prova de Escrita por INSE

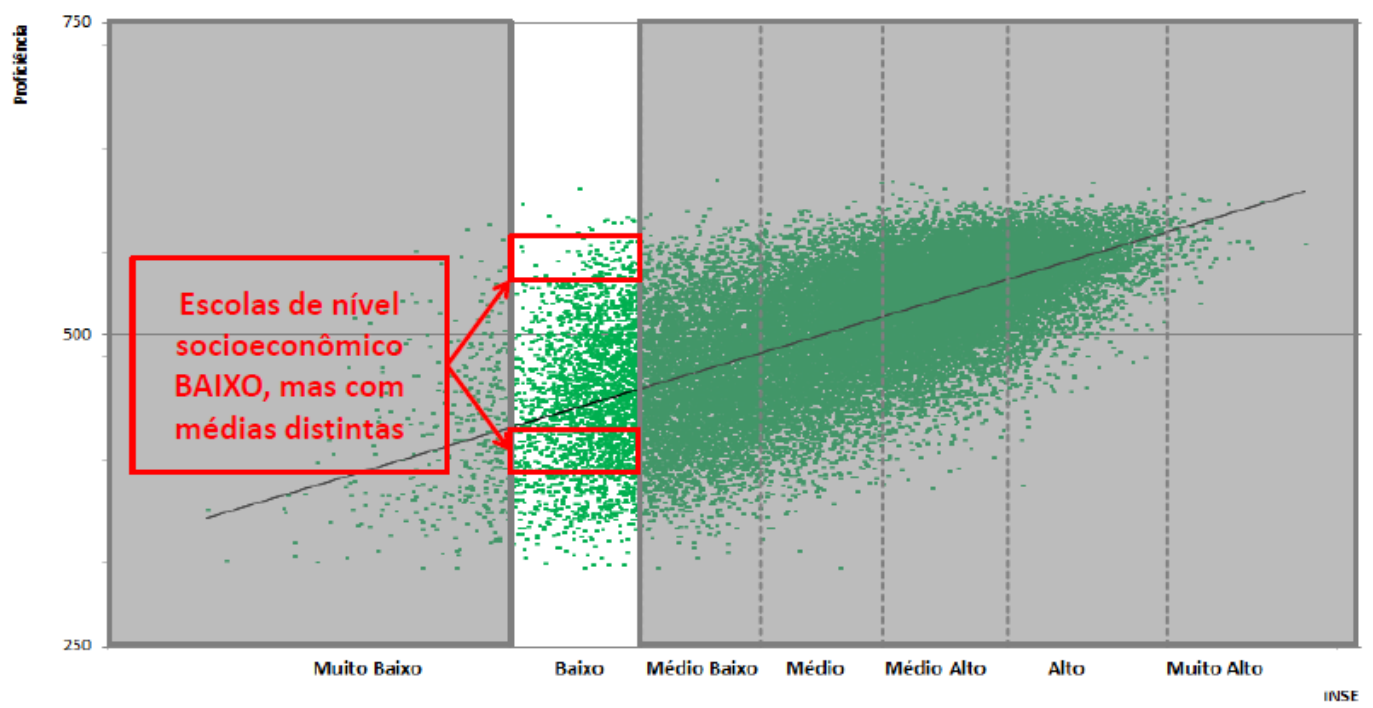

BRASIL Média por escola na prova de Leitura por INSE

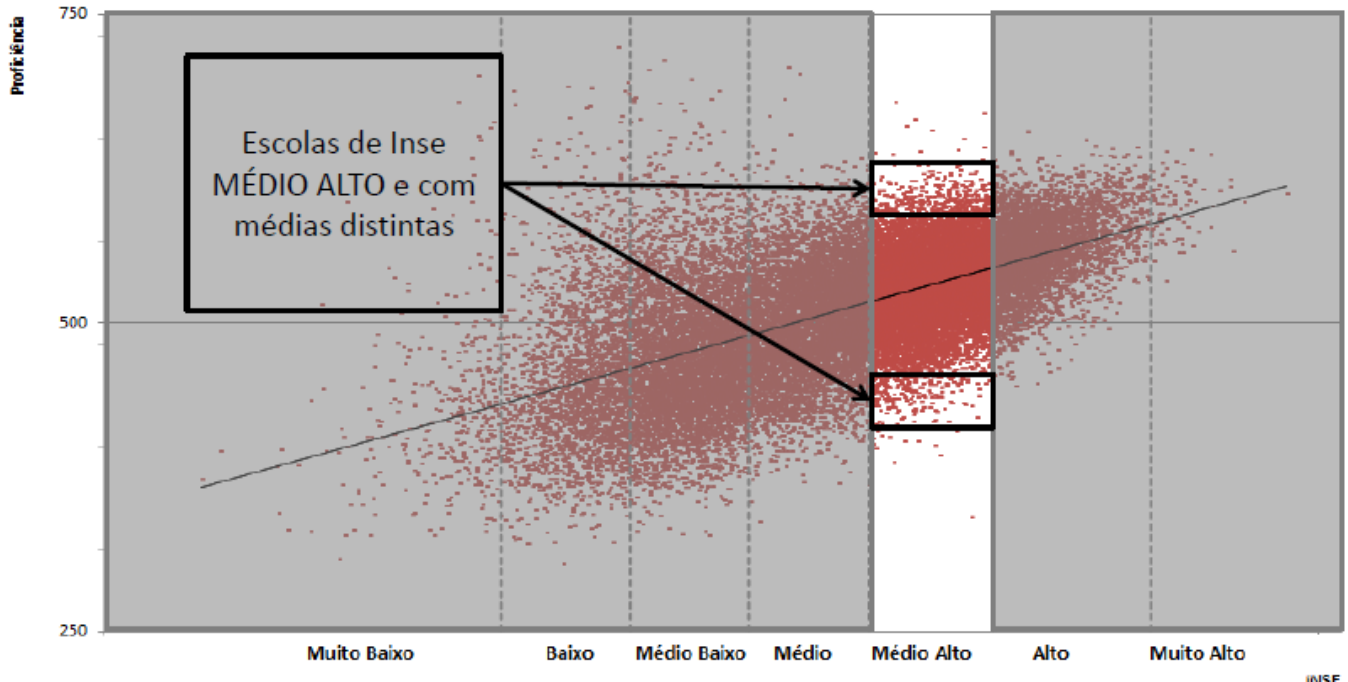

Fonte: Brasil (2015c).

O caráter, por assim dizer, moral ou moralizador do dado numérico também exerce força no processo de condução das condutas cada vez mais detalhistas, visando à melhoria da eficácia e, 
portanto, da qualidade da educação. Se por moral entendermos "[...] um conjunto de valores e regras de ação propostas aos indivíduos e às comunidades por intermédio de aparelhos prescritivos diversos - como podem ser as instituições educativas, as associações científicas, instâncias públicas de gestão [...]" (BELLO, 2012, p.25), podemos considerar que as estatísticas possuem esse viés moral ou moralizante, na medida em que visibilizam, mesmo que difusamente, uma regra de conduta, um princípio, uma prescrição de elevado valor social. Identificar e disseminar as "boas práticas", por exemplo, que resultariam em "bons resultados" nos testes, funcionaria como um princípio de conduta. Essas "boas práticas" indicariam regras a serem seguidas, comportamentos a serem realizados. Foucault (2012) argumenta que a relação que o indivíduo estabelece com essas regras, ou seja, seu comportamento, também, pode ser entendido como "moral". Nesse sentido, somos levados a avaliar e decidir quais regras seguir. O dito caráter moral dos números opera nessa “conjuntura normativa”, tornando-se uma boa razão e um “[...] princípio de conduta desejável à constituição do bom professor" (BELLO, 2012, p.25), da boa escola, do bom ensino.

Nesse sentido, se em condições contextuais semelhantes as escolas atingem diferentes desempenhos nos testes das avaliações em larga escala, infere-se que a diferença está "na realidade" escolar, nas práticas de gestão e de ensino. Desse modo, identificar estatisticamente as "boas práticas" permite produzir um entrelaçamento entre os índices produzidos e o discurso pedagógico, a fim de buscar justificativas para os índices baixos e promover as práticas pedagógicas que resultaram em altos índices, criando, assim,

“[...] um sistema de razão que rege [...] a maneira segundo a qual constituem-se problemas sobre os quais se deve agir e ordena os objetos e características das pessoas sobre as quais se deve agir, as relações por meio das quais causas são determinadas e problemas remediados e os caminhos para as próprias possibilidades de mudança" (POPKEWITZ; LINDBLAD, 2001, p. 112).

É a partir da possibilidade da comparação - que não apenas indica ao governo onde agir que se emite um alerta aos indivíduos para que olhem para suas próprias práticas, para a organização da sua escola, a fim de modificarem essas práticas visando, como horizonte, a alfabetização das crianças. E, consequentemente, o gerenciamento do risco do analfabetismo infantil. 


\section{CONSIDERAÇÕES FINAIS}

Diante do que foi analisado neste texto, considera-se que a ANA funciona como um instrumento de quantificação e que atua na produção do risco do analfabetismo infantil, colocando em operação estratégias para gerenciar esse risco.

As condições para a produção do risco do analfabetismo infantil são possibilitadas ao se considerar a alfabetização e as habilidades de leitura e escrita como saberes estratégicos para a população, pois permitiriam maior possibilidade de sucesso no restante da escolarização, uma melhoria no desempenho nas avaliações da educação básica, promoveriam a formação cidadã e se configurariam como uma forma de investimento em capital humano.

As três estratégias de gerenciamento do risco do analfabetismo infantil articuladas pretendem dar visibilidade a esse risco através da divulgação dos dados da ANA e das formas de convocação da sociedade - de todos e de cada um - para uma vigilância constante desses índices. Além disso, tomar a aprendizagem do aluno como um direito convoca os indivíduos a administrar o risco do analfabetismo infantil na medida em que esse direito garantiria, não apenas discursivamente bons resultados nas avaliações que medem a alfabetização das crianças; mas também impulsionaria o seu sucesso no restante da escolarização. Por fim, a comparação - a partir dos dados contextualizados produzidos pelo INEP - se torna um movimento recorrentemente mobilizado com a finalidade não apenas de indicar ao governo onde agir, mas também de focalizar as práticas docentes, administrativas, gestoras, pedagógicas, avaliativas, etc., exercidas no ambiente escolar visando a identificação de "boas práticas" que pudessem contribuir com a alfabetização das crianças e, consequentemente, com o gerenciamento do risco do analfabetismo infantil. 


\section{Referências}

BELLO, Samuel Edmundo Lopez. As práticas curriculares em Matemática que se produzem pelo governo do IDEB. Horizontes. Universidade São Francisco: Bragança Paulista-SP, v. 30, n. 2, p. 19-30, jul./dez. 2012.

; SPERRHAKE, Renata. Educação e risco social na curricularização do saber estatístico no Brasil. Acta Scientiarum Education. Maringá, v. 38, n. 4, p. 415-424, Oct.-Dec. 2016.

BRASIL. Ministério da Educação (MEC). Portaria 867, de 4 de julho de 2012. Institui o Pacto Nacional pela Alfabetização na Idade Certa e as ações do Pacto e define suas diretrizes gerais. Diário Oficial [da República Federativa do Brasil], Brasília, DF, n.129, 5 jul. 2012.

; Instituto Nacional de Estudos e Pesquisas Educacionais Anísio Teixeira - INEP. Avaliação Nacional da Alfabetização - ANA - Documento Básico. Brasília, 2013a, 20pp. Disponível em: 〈http://download.inep.gov.br/ educacao basica/saeb/2013/livreto_ANA online.pdf>. Acesso em: 25 out. 2016.

; Instituto Nacional de Estudos e Pesquisas Educacionais Anísio Teixeira - INEP. Nota técnica: escolas similares. Brasília, 2013b, $6 \mathrm{pp}$.

Portaria 468, de 19 de setembro de 2014. Estabelece a sistemática para a realização da edição 2014 da Avaliação Nacional de Alfabetização (ANA). Diário Oficial, Brasília, DF, n.182, 22 set. 2014.

; Instituto Nacional de Estudos e Pesquisas Educacionais Anísio Teixeira - INEP. Relatório ANA 2013-2014: Volume 1 - Da concepção a realização. Brasília, 2015a, 122pp.

; Instituto Nacional de Estudos e Pesquisas Educacionais Anísio Teixeira - INEP. Relatório ANA 2013-2014: Volume 2 - Análise dos resultados. Brasília, 2015b, 124 pp.

; Instituto Nacional de Estudos e Pesquisas Educacionais Anísio Teixeira - INEP. Avaliação Nacional da Alfabetização 2014 (pdf). 2015c. Disponível em: <http://portal.mec.gov.br/index.php?option=com_docman\& view= download\&alias=21091-apresentacao-ana-15-pdf\&category_slug=setembro-2015-pdf\&Itemid=30192>. Acesso em: 25 out. 2016.

CASTRO, Maria Helena Guimarães de. A Consolidação da Política de Avaliação da Educação Básica no Brasil. In: BROOKE, Nigel; ALVES, Maria Teresa Gonzaga; OLIVEIRA, Lina Kátia Mesquita de (Orgs.). A Avaliação da Educação Básica: a experiência brasileira. 1.ed. Belo Horizonte, MG: Fino Traço, p.131-143, 2015.

CAMINI, Patrícia. Por uma problematização da classificação da escritas infantis em níveis psicogenéticos. Porto Alegre, 2015. 155 f. Tese (Doutorado em Educação) - Universidade Federal do Rio Grande do Sul. Faculdade de Educação. Programa de Pós-Graduação em Educação, Porto Alegre, 2015.

FERRARO, Alceu Ravanello. História Inacabada do analfabetismo no Brasil. São Paulo: Cortez, 2009.

FOUCAULT, Michel. Nascimento da Biopolítica: curso no Collège de France (1978-1979). Tradução de Eduardo Brandão. São Paulo: Martins Fontes, 2008.

. Vigiar e Punir: nascimento da prisão. Tradução de Raquel Ramalhete. 36 ed. Petrópolis: Vozes, 2009.

Ditos e Escritos, volume V: ética. sexualidade. política. Tradução: Elisa Monteiro, Inês Autran Dourado Barbosa. 3 ed. Rio de Janeiro: Forense Universitária, 2012.

Ditos e Escritos, volume IV: estratégia, poder-saber. Tradução: Vera Lucia Avellar Ribeiro. 3. ed. Rio de Janeiro: Forense Universitária, 2015.

GIL, Natalia. Razão em números: a presença das estatísticas nos discursos educacionais divulgados na Revista Brasileira de Estudos Pedagógicos (1944-1952). São Paulo, SP. 2002. Dissertação (Mestrado em Educação). 180f. Faculdade de Educação da Universidade de São Paulo, São Paulo, 2002.

. A dimensão da educação nacional: um estudo sócio-histórico das estatísticas oficiais da escola brasileira. São Paulo, SP. 2007. Tese (Doutorado em Educação). 409f. Faculdade de Educação da Universidade de São Paulo, São Paulo, 2007.

HATTGE, Morgana Domênica. Performatividade e inclusão no movimento todos pela educação. 2014.182 f.; Tese (Doutorado em Educação) - Universidade do Vale do Rio dos Sinos. Programa de Pós-Graduação em Educação, São Leopoldo, RS, 2014. 
LOCKMANN, Kamila. A proliferação das Políticas de Assistência Social na Educação Escolarizada: estratégias da governamentalidade neoliberal. Porto Alegre, 2013. 317 f. Tese (Doutorado em Educação) - Universidade Federal do Rio Grande do Sul. Faculdade de Educação, Porto Alegre, 2013.

. A inclusão escolas e as avaliações em larga escala: uma díade que produz efeitos na escola. In: Anais da $38^{\circ}$ Reunião Nacional da ANPEd: Democracia em risco: a pesquisa e a pós-graduação em contexto de resistência. 2017 , 14p. Disponível em: < http://38reuniao.anped.org.br/sites/default/files/resources/programacao/trabalho_38anped_2017 GT13_122.pdf>. Acesso em 04 de setembro de 2018.

POPKEWITZ, T.; LINDBLAD, S. Estatísticas educacionais como um sistema de razão: relações entre governo da educação e inclusão e exclusão sociais. Educação e Sociedade, São Paulo, ano XXII, n. 75, Ago. 2001.

RIBEIRO, Vera Masagão; LIMA, Ana Lúcia D’Império; BATISTA, Antônio Augusto Gomes. (Org.). Alfabetismo e letramento no Brasil: 10 anos do INAF. Belo Horizonte: Autêntica Editora, 2015.

ROSE, Nikolas. Governando a alma: a formação do eu privado. In: SILVA, Tomaz Tadeu. (Org.). Liberdades Reguladas: a pedagogia construtivista e outras formas de governo do eu. Petrópolis: Vozes, 1998, p. 30-45.

SOARES, Magda. Letramento: um tema em três gêneros. Belo Horizonte: Autêntica, 2006.

. Alfabetização: a questão dos métodos. São Paulo: Contexto, 2016.

SOARES, José Francisco; ALVES, Maria Teresa Gonzaga. Efeitos de escolas e municípios na qualidade do ensino fundamental. Cadernos de Pesquisa, v.43, n. 149, p. 492-517, maio/ago., 2013.

SPERRHAKE, Renata. O saber estatístico como dizer verdadeiro sobre a alfabetização, o analfabetismo e o alfabetismo/letramento. Porto Alegre, 2013. 133 f. Dissertação (Mestrado em Educação) - Universidade Federal do Rio Grande do Sul. Programa de Pós-Graduação em Educação, Porto Alegre, 2013.

; TRAVERSINI, Clarice Salete. Os critérios do Censo produzindo estatísticas de alfabetização: gerenciar o risco e inventar pessoas. Estatística e Sociedade, Porto Alegre, n. 2, p. 142-156, nov. 2012.

TODOS PELA EDUCAÇÃO. Todos Pela Educação. 5 anos, 5 metas, 5 bandeiras. São Paulo: Todos Pela Educação, 119. p., 2011.

TRAVERSINI, Clarice; BELLO, Samuel Edmundo L. O numerável, o mensurável e o auditável: estatística como tecnologia para governar. In: Educação e Realidade, Porto Alegre, n. 34, n. 2, maio/ago., 2009. 


\section{RESUMO}

Este texto objetiva analisar a produção do risco do analfabetismo infantil e as estratégias de gerenciamento desse risco postas em funcionamento pela Avaliação Nacional da Alfabetização (ANA). Metodologicamente, e através de uma analítica-interpretativa de viés foucaultiano, analisaram-se documentos da ANA tais como portarias, notas explicativas, relatórios. As análises evidenciam três estratégias que convocam os indivíduos a combaterem o risco do analfabetismo infantil, quais sejam: 1) a visibilização e vigilância do risco; 2) a aprendizagem como direito e 3) a comparação dos resultados. Conclui-se que a combinação dessas diferentes estratégias, possibilitada pela produção quantitativa do processo avaliativo em larga escala, produz discursivamente o risco do analfabetismo infantil.

Palavras-chave: Avaliações externas em larga escala. Estudos Foucaultianos. Alfabetização.

\section{EVALUACIÓN NACIONAL DE LA ALFABETIZACIÓN: PRODUCCIÓN Y GESTIÓN DEL RIESGO DEL ANALFABETISMO INFANTIL}

\section{RESUMEN}

El objetivo de este artículo es analizar la producción del riesgo del analfabetismo infantil y de sus estrategias de gestión que se ponen en funcionamiento en la Evaluación Nacional de Alfabetización (ANA), Metodológicamente, y a través de una analítica-interpretativa de sesgo foucaultiano, fueron analizados documentos de dicha evaluación tales como: Resoluciones, notas explicativas, informes, etc. Los análisis evidencian tres estrategias que convocan a los individuos a combatir el riesgo del analfabetismo infantil, entre ellas: 1) la visibilización y vigilancia del riesgo; 2) el aprendizaje como derecho y 3) la comparación de los resultados. Se concluye que la combinación de esas diferentes estrategias, posibilitada por la producción cuantitativa del proceso de evaluación a gran escala, produce discursivamente el riesgo del analfabetismo infantil.

Palavras-clave: Evaluación a gran escala. Estudos Foucaultianos. Alfabetización.

\section{NATIONAL EVALUATION OF LITERACY: PRODUCTION AND MANAGEMENT OF THE RISK OF CHILD ILLITERACY}

\section{ABSTRACT}

This paper aims at analysing the production of the risk of child illiteracy and the risk management strategies put both into working by the National Literacy Assessment (ANA). Methodologically, and through an analyticinterpretative of Foucauldian bias, ANA documents such as ordinances, explanatory notes, reports were analysed. Our analyses show three strategies that convene individuals to combat the risk of child illiteracy, which are: 1) the visibility and surveillance of risk; 2) learning as a right and 3) the comparison of results. We concluded that the combination of these different strategies, which are possible by the quantitative production of the evaluation process on a large scale, discursively produces the risk of child illiteracy.

Keywords: Large-scale external evaluation. Foucauldian studies. Literacy. 